\title{
*UCLPRESS
}

Article title: Publicly available data sources to compile an urban natural capital account according to the SEEA EEA: A London case study

Authors: Emily Northridge[1], Mikaël J. A. Maes[2], Ben Milligan[3]

Affiliations: University College London[1], University of New South Wales[2]

Orcid ids: 0000-0002-0419-4514[2], 0000-0003-1313-3956[3]

Contact e-mail: mikael.maes.16@ucl.ac.uk

License information: This is an open access article distributed under the terms of the Creative Commons Attribution License (CC BY) $4.0 \mathrm{https://creativecommons.org/licenses/by/4.0/,} \mathrm{which} \mathrm{permits} \mathrm{unrestricted} \mathrm{use,} \mathrm{distribution} \mathrm{and}$ reproduction in any medium, provided the original author and source are credited.

Preprint statement: This article is a preprint and has not been peer-reviewed, under consideration and submitted to UCL Open: Environment Preprint for open peer review.

Funder: London Natural Environment Research Council Doctoral Training Programme

DOI: $10.14324 / 111.444 / 000055 . v 1$

Preprint first posted online: 28 August 2020

Keywords: natural capital, environmental accounting, ecosystem accounting, ecosystem services, urban, London, United Kingdom, SEEA, SEEA EEA, Environmental economics, Environmental policy and practice, Public policymaking, Built environment, Sustainability 
Professor Dan Osborn, Editor-In-Chief, UCL Open: Environment

$28^{\text {th }}$ August 2020

\section{Re. Submission of manuscript, 'Publicly available data sources to compile an urban natural capital account according to the SEEA EEA: A London case study'.}

Dear Prof Dan Osborn,

We are writing to submit our manuscript, 'Publicly available data sources to compile an urban natural capital account according to the SEEA EEA: A London case study', by Emily Northridge, Mikaël J. A. Maes and Ben Milligan for consideration for publication in UCL Open: Environment. Our manuscript explores whether existing publicly available data sources on London's natural capital are sufficient to compile an inclusive natural capital account according to the United Nations System of Environmental-Economic Accounting Experimental Ecosystem Accounting (SEEA EEA) framework. This is particularly relevant as more and more organisations seek to develop standardised environmental accounts to encourage sustainable land use choices and improve management of the natural environment and associated benefits, including in urban areas such as London.

In light of this attention, our manuscript is one of the first systematic assessments of publicly available data sources relevant for natural capital accounting in London, United Kingdom. We critically analysed publicly available data sources and found at least 66 data sources relevant for compiling an urban natural capital account for London. However, our analysis also showed that it was not possible to compile an inclusive natural capital account for London for each year consistent according to the SEEA EEA framework. This was mainly because of issues related to temporal inconsistencies, land cover classifications and key non-publicly available data sources. Our paper highlights the need for renewed collaboration across disciplines and sectors to develop better publicly available data sources underpinned by a cohesive classification framework for urban areas.

We confirm that this manuscript has not been previously published elsewhere and is not under consideration by any other journal. All authors have approved this manuscript and agree with its submission to UCL Open:

Environment. We look forward to hearing from you soon.

Yours sincerely,

Ms Emily Northridge, Mr Mikaël J. A. Maes and Dr Ben Milligan 


\title{
Publicly available data sources to compile an urban natural capital account according to the SEEA EEA: A London case study
}

Emily Northridge ${ }^{1}$, Mikaël J. A. Maes ${ }^{2,3,4^{*}}$ and Ben Milligan ${ }^{5 *}$

${ }^{1}$ Centre for Law and Environment, University College London, Bentham House, Endsleigh Gardens, London WC1H OEG, United Kingdom.

${ }^{2}$ Department of Geography, University College London, Pearson Building, Gower Street, London, WC1E 6BT, United Kingdom.

${ }^{3}$ Centre for Biodiversity and Environment Research, Department of Genetics, Evolution and Environment, University College London, Gower Street, London, WC1E 6BT, United Kingdom.

${ }^{4} \mathrm{MRC}$ Centre for Environment and Health, School of Public Health, Faculty of Medicine, Imperial College London, Norfolk Place, London W2 1PG, United Kingdom.

${ }^{5}$ University of New South Wales Law School, Law Building, UNSW Sydney, NSW 2052, Australia

*Corresponding authors: mikael.maes.16@ucl.ac.uk and b.milligan@unsw.edu.au (Tel: +61 29385

2227)

Word Count (Items): Total - 5,008 (Abstract - 248; Main Text -4,155; References - 605).

\begin{abstract}
Government organisations and other public sector bodies are compiling standardised environmental accounts to encourage more sustainable land use choices and improve management of the natural environment and associated benefits. While the United Nations System of Environmental-Economic Accounting Experimental Ecosystem accounting (SEEA EEA) provides such as framework, practical challenges remain in particular decision-making contexts. In urban areas, natural ecosystems have unique challenges because of anthropogenic pressures, providing a mix of ecosystem services (ES) that may be valued differently compared to non-urban natural ecosystems due to people's proximity to these. It is unknown whether existing publicly available data sources for urban areas are compatible with the SEEA EEA framework and if these sources are sufficient for the development of an inclusive natural capital accounts. Here, we explore whether an inclusive urban natural capital account that includes a broad range of ES can be compiled from publicly available data sources for Greater London between 2007 and 2018. We showed that it was not possible to compile an inclusive urban natural capital account for London per year consistent with the SEEA EEA framework because of issues with (1) temporal inconsistencies, (2) land cover classifications and (3) lack of public access to certain data sources. Greater collaboration between institutions and other organisations could support our understanding of linkages between ecosystem extent, condition and ES flows. Overall, our findings suggest the need for renewed efforts to develop a cohesive source of publicly available data, which could be supported by making interdisciplinary work standard practise.
\end{abstract}

Keywords: Natural capital, environmental accounting, ecosystem accounting, ecosystem services, urban, London, United Kingdom, SEEA, SEEA EEA 


\section{INTRODUCTION}

Natural capital describes those parts of the natural environment that are capable of contributing to human health and well-being (Natural Capital Committee [NCC], 2013). The benefits that flow from natural capital assets are known as ecosystem services (ES) and are classified into three distinct categories, i.e. (1) provisioning services which include all physical products that we take from the environment, (2) regulating services which maintain environmental processes and sustain the biophysical environment, and (3) cultural services which are the non-material amenities that people gain from interacting with ecosystems (Haines-Young and Potschin, 2018). Some sources recognise a fourth ES category, i.e. supporting services which are defined as the services that maintain earth's conditions so that all other ES can flow (Millenium Ecosystem Assessment [MEA], 2005). Degradation of nature — on which society and the economy as a whole depends upon — in favour of land uses which produce marketable goods has resulting in a $60 \%$ decline in ES productivity compared to 50 years ago (MEA, 2005). Identifying the value that natural capital gives to a country is crucial to understand its contributions to human health and well-being and preventing further losses (Stiglitz et al., 2010).

Global commitments are being made by decision-makers to include the value of natural capital into (inter)national accounting practices and GDP calculations-for example, United Nations (UN) Sustainable Develop Goal Targets 15.9 and 17.19 and Aichi Biodiversity Target 2 (CBD, 2010; UN, 2015). The European Union's Biodiversity Strategy posits to 'integrate ecosystems and their services into national and EU accounting and reporting systems' (EC, 2011), and the United Kingdom's (UK) 25 Year Environment Plan states to use 'natural capital approaches to help encourage better uptake of natural capital reporting, standards and accounting across government and business' (Department for Environment, Food \& Rural Affairs [Defra], 2018). On a city level, the Greater London Authority (GLA) made commitments to 'promote a natural capital accounting framework for London' (GLA, 2018). Although institutional commitments have been made to account for natural capital across all levels of governance, accounting for the ES flowing from natural capital in terms of national wealth is so far not globally practised.

The UN collaborated with national statistical offices and a wide range of other organisations to develop a statistical framework for valuing natural resources and land in a way that is compatible with the System of National Accounts (SNA). The System of Environmental-Economic Accounting Central Framework (SEEA CF) is a statistical framework that sets standardised concepts, definitions, classifications and accounting rules to enable countries to produce transnationally comparable statistics on their environmental-economic system (UN, 2014a). However, the contribution of most regulating and cultural ES, as well as certain provisioning ES, are currently unrecognised within the SEEA CF. The System of Environmental-Economic Accounting Experimental Ecosystem Accounting framework (SEEA EEA) presented efforts to account for the complete environmental-economic system (UN, 2014b) and is compatible with the structure of the SEEA CF. It enables decision-makers to better understand the value of their natural capital assets and improve decision-making beyond environmental policies (Vardon et al., 2017). So far, more than 24 countries have compiled SEEA EEA accounts, even though all vary in scope and resolution (Hein et al., 2020). Meanwhile, experts engaged in extensive discussions and testing of concepts to further advance the SEEA EEA, and a revised SEEA EEA is expected to be completed in 2021 (UN, 2020, 2019). 
The UK Office for National Statistics (ONS) has worked with Defra, using the SEEA EEA framework, to develop accounts for the value of urban natural capital assets. This has resulted in a growing range of work focusing on understanding the value of urban natural capital in the UK (EFTEC, 2017; ONS, 2019; Vivid Economics, 2017). These urban environmental accounts are useful for understanding the value of urban natural capital. However not all were compiled in a way consistent with the SEEA EEA framework. Here, we explore whether it is possible to (1) compile an urban natural capital account according to the SEEA EEA framework from publicly available data sources for London and (2) use of the SEEA EEA framework to capture the value of individual ecosystem assets at a reasonable spatial granularity in an urban context.

\section{METHODS}

We identified publicly available data sources relevant to compile an urban natural capital account according to SEEA EEA through reports and studies using the Google Scholar search engine and government open data records. The ecosystem accounting area considered in this analysis is Greater London (UK), which is defined here as the 32 London boroughs and the City of London. We contacted experts and organisations that deal with environmental data sources or have expertise in environmental accounting for input; we specifically contacted Defra, Geofabrik, Greenspace Information for Greater London (GiGL), the Ordnance Survey (OS), Sustain and Thames Water. We only included publicly available data sources if these sources were published between 2007 and 2018. We did not seek to make a definitive statement on the number of publicly available data sources, because there are privately-owned data sources that might be available after usage is granted by the data owner. We also included publicly available data sources with only partial spatial or temporal cover for Greater London and gathered information for each mapped data source, if applicable, on authorship, update frequency, spatial extent, unit or resolution, data format (e.g. raster, vector format), licensing or usage restrictions and historic data availability (ESM Appendix, Table 1 and 2).

\subsection{ECOSYSTEM EXTENT}

Land cover classifications described in the SEEA CF and SEEA EEA bring about issues when developing an urban natural capital account. For example, the land cover class 'artificial surfaces' is useful when assessing urban areas on a national and international scale; however, this land cover class may not useful when developing a natural capital account on an urban scale because it may exclude smaller green spaces. The land cover classifications from the SEEA CF and SEEA EEA were either (1) too detailed for use as a land cover classification in an urban context or (2) not applicable to the area of Greater London (e.g. mangroves). The SEEA framework aims to be comprehensive, meaning it accounts for all land cover classifications within the ecosystem accounting area. Considering the issues with land cover classifications from the SEEA CF and SEEA EEA in an urban context, we therefore used the land cover classifications from these frameworks to develop a simplified urban land cover classification (Figure 1) (UN, 2014a, 2014b). We excluded the following land cover classes from our analysis: barren land, coastal water bodies, mangroves, permanent snow and glaciers, sea and sparsely vegetated areas. We also added two land cover classes specifically for data sources without identifiable land covers (i.e. unspecified green and blue space) (Figure 1). This is consistent with suggestions from SEEA experts to define urban land cover based on (1) natural and semi-natural land covers which more or less retain natural features and (2) urban green and blue land covers which are embedded in the built-up urban area and are significantly altered or managed to be 
classified as a natural or semi-natural land cover (Wang et al., 2019). Finally, we identified all publicly available data sources that provide spatially explicit land covers based on our urban land cover classification per year. We classified data sources which did not specify a year when created in our results as unclassified (U).

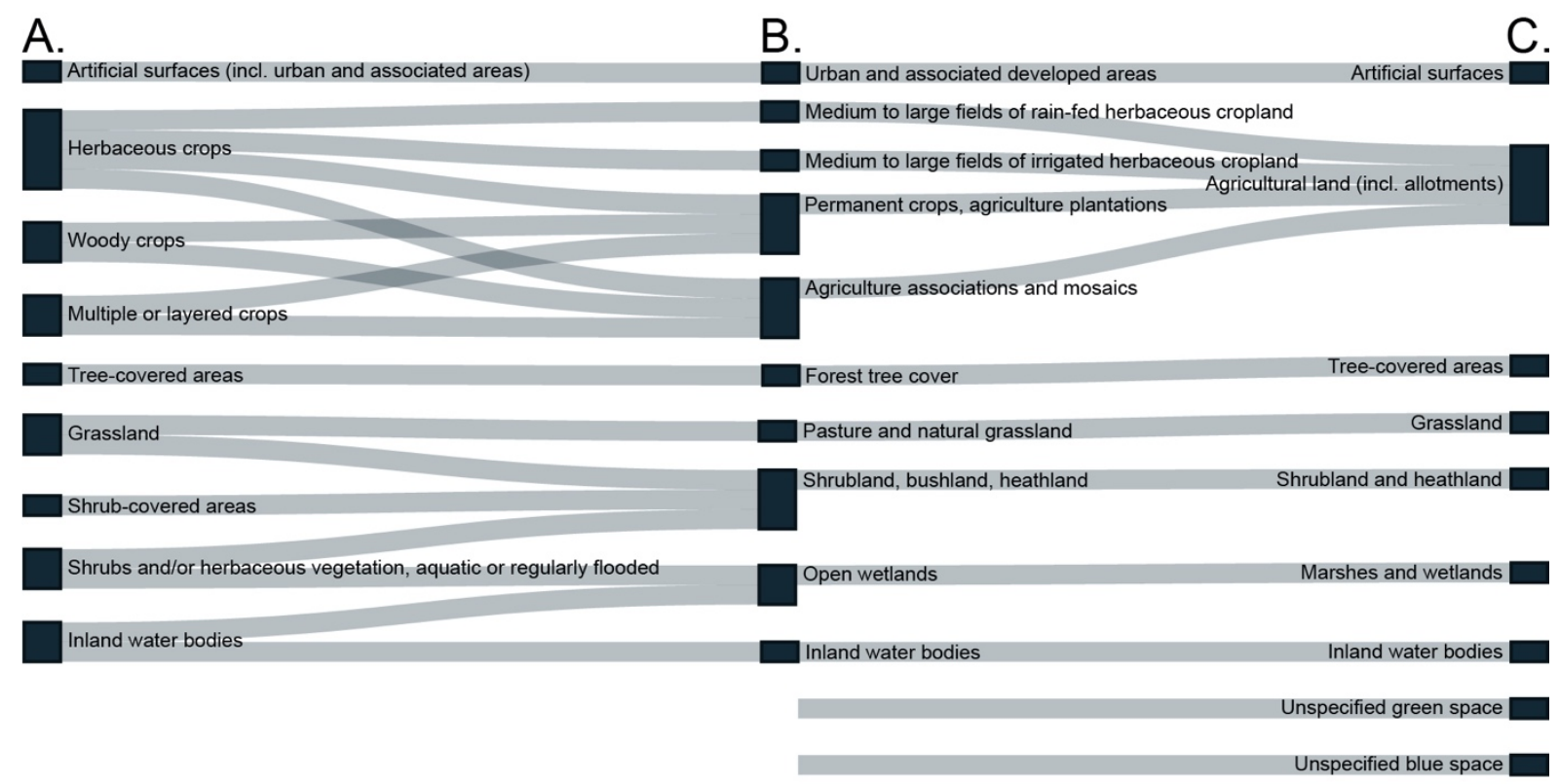

Figure 1. Connecting different land cover classifications. Overview and connections between the (A) land cover classification based on the System of Environmental-Economic Accounting Central Framework (SEEA CF), (B) land cover/ecosystem functional unit classes from the System of Environmental-Economic Accounting Experimental Ecosystem Accounting and (C) our simplified urban land cover classification (UN, 2014a, 2014b). Our urban land cover classification did not include the following land cover classes: barren land, coastal water bodies, mangroves, permanent snow and glaciers, sea and sparsely vegetated areas. We also specified two land cover classes specifically for data sources without identifiable land covers (i.e. unspecified green and blue space).

\subsection{ECOSYSTEM CONDITION}

Although not the only definition, ecosystem condition is broadly defined as the capacity of ecosystems to provide ES (UN, 2014a, 2014b). We identified data sources relevant to ecosystem condition by assessing which ecosystem condition is applicable per year. We classified data sources which did not specify a year when created in our results as unclassified (U). We included publicly available imagery from satellites because this data type can be used for assessing ecosystem extent and condition. Specific wavelengths of satellite imagery, for example, can be used to calculate vegetation indices such as the Normalised Difference Vegetation Index (NDVI). NDVI is based on the process where healthy vegetation absorbs more light in the photosynthetically active region compared to degraded vegetation or non-vegetated area and is therefore a proxy for measuring ecological extent and condition of unspecified green space (Kriegler et al., 1969). Specifically, it can be used to assess vegetation productivity, and in combination with surface land temperature to develop soil moisture indicators (Han et al., 2010; Pettorelli et al., 2005).

\subsection{ECOSYSTEM SERVICE FLOWS}

We identified publicly available data sources relevant to estimating ES flow from natural capital assets and what ES class it belonged to (i.e. provisioning, regulating or cultural ES). We based classification of ES flows on the Common International Classification of Ecosystem Services (CICES) (Haines-Young and Potschin, 2018). As we do not seek to make a definitive statement of which ES based on CICES are 
relevant to urban natural capital accounts, a single publicly available data source was considered sufficient to indicate the possibility to assess a particular ES flow. Several reports have developed urban natural capital accounts in London and the UK (EFTEC, 2017; ONS, 2019; Vivid Economics, 2017a). However, these reports only focus on a limited number of ES flows and do not include the complete list of ES according to CICES. We simply added those ES for which we found publicly available data sources, but we acknowledge that other ES may be relevant to develop an inclusive urban natural capital account. We also did not explore the potential for modelling and other analytical techniques to provide ES unit values and factors.

\subsection{URBAN NATURAL CAPITAL ACCOUNTS FOR LONDON}

We developed a matrix linking ecosystem extent and condition with ES flows based on similar approach in a scoping study to develop an urban natural capital account for the whole of the UK (ESM Appendix, Table 3) (EFTEC, 2017). This matrix then formed the basis for assessing the possibility to develop an urban natural capital account for London per year.

\section{RESULTS}

Our analysis found 66 publicly available data sources relevant to compile an urban natural capital account for London based on the SEEA EEA framework. Of these, 29 data sources were relevant to ecosystem extent, 23 to ecosystem condition and 16 to ES flows.

\subsection{ECOSYSTEM EXTENT}

Our results showed that it is possible to measure ecosystem extent for all 7 land cover classes per year (Figure 2A). However, the overall number of data sources per land cover class was low. A high number of identified data sources did not specify a particular land cover class and were therefore classified as unspecified green or blue space. In addition, certain data sources seemed useful for determining ecosystem extent at first but are not useful after detailed analysis. For example, the global land cover maps from the European Space Agency (ESA) Climate Change Initiative (CCI) identified all 7 land cover classes for all years between 2007 and 2018 (ESA, 2017). However, the coarse spatial resolution (300 $\mathrm{m}$ per pixel) of this data source makes it extremely granular for urban ecosystem accounting in Greater London and a large part of London was classified as urban area. Meanwhile, the Land Cover Map released by the UK Centre for Ecology \& Hydrology had a detailed land cover classification, but a poor temporal availability (i.e. a land cover classification for the years 2007 and 2015) (CEH, 2017). We therefore identified several data sources with high-quality spatial resolution but low-quality time series to assess ecosystem extent, while one data source had a high-quality time series but a lowquality spatial resolution (Figure $2 \mathrm{~B}$ ). 


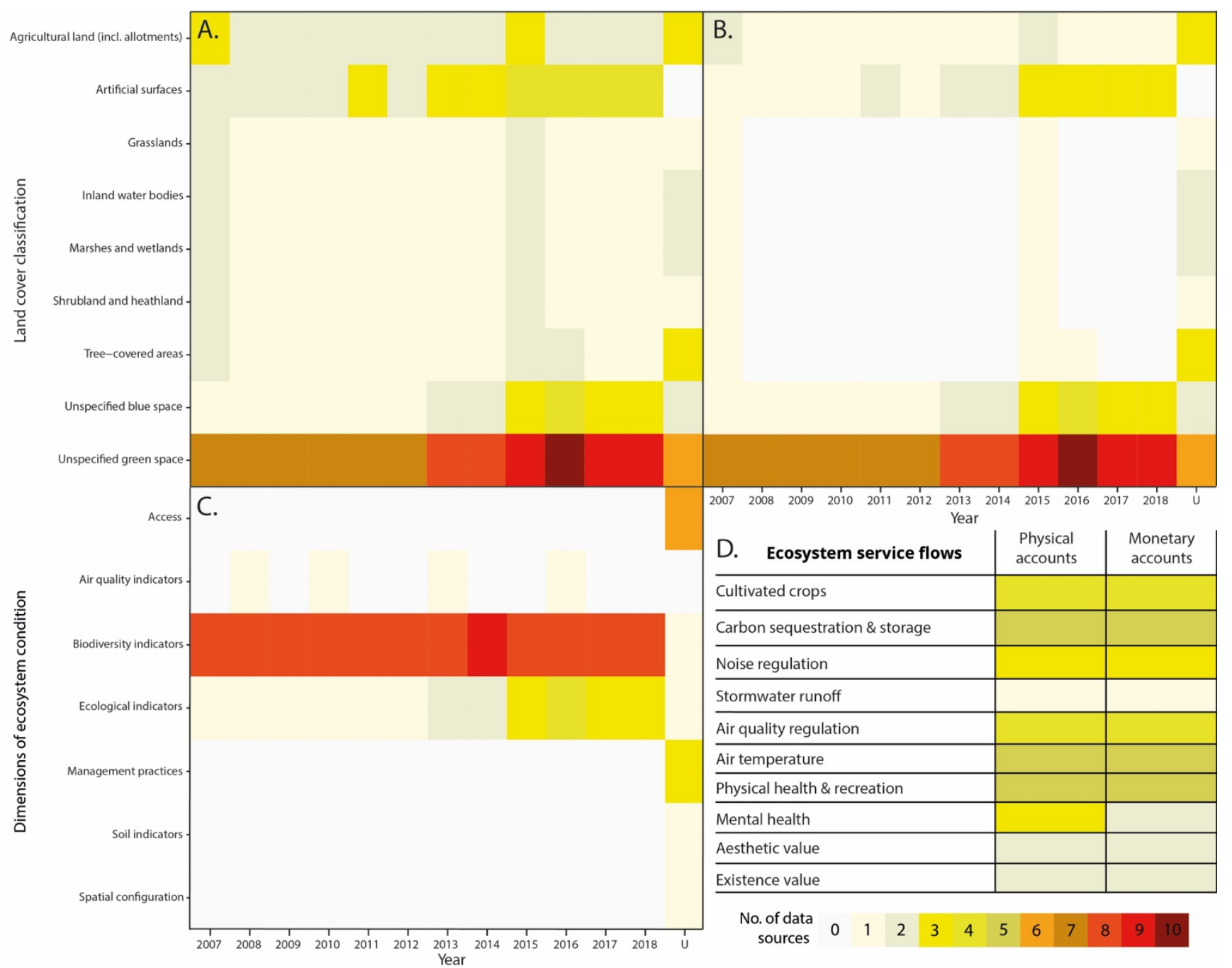

Figure 2. Amount of publicly available data sources on ecosystem extent, condition and ecosystem service flows per year. All identified publicly available data sources for (A) ecosystem extent, (B) ecosystem extent excluding land cover maps from the European Space Agency Climate Change Initiative (ESA, 2017), (C) broad dimensions of ecosystem condition and (D) ecosystem service flows in biophysical and monetary terms. Data sources without an identifiable year were marked as unclassified or ' $U$ '. Data sources without an identifiable urban land cover classification were classified as 'unspecified green space' or 'unspecified blue space'. 


\subsection{ECOSYSTEM CONDITION}

We identified only two broad dimensions of ecosystem condition that can be assessed on a yearly basis based on the identified data sources, i.e. biodiversity indicators and ecological condition (Figure 2C). We also identified that air quality indicators could be assessed for several years (i.e. 2008, 2010, 2013 and 2016) through a single data source called the London Atmospheric Emissions Inventory. All other data sources on ecosystem condition were found to have no identifiable year. However, some experts argue that particular ecosystem extent and conditions indicators may not change that oftenparticularly in urban areas-suggesting these could be used for multiple years. Some data sources also seemed useful for determining particular indicators of ecosystem condition but were considered less useful after detailed analysis. For example, a large part of the point and polygon species records from GIGL were collected before 2007, and sightings between 2007 and 2018 were often based on observations from volunteers, resulting in varying record counts between London boroughs (GIGL, 2017).

\subsection{ECOSYSTEM SERVICE FLOWS}

We identified 4, 8 and 9 publicly available data sources relevant to develop provisioning, regulating and cultural ES, respectively (Figure 2D). We found substantially more regulating and cultural ES compared to provisioning ES, which may suggest urban ecosystems are much less important for delivering direct benefits to human health and well-being such as biotic and abiotic goods (e.g. biomass and water), and are more important for delivering indirect benefits to human health and wellbeing (e.g. noise regulation, air temperature, physical or mental health).

\subsection{URBAN NATURAL CAPITAL ACCOUNTS FOR LONDON}

By combining all publicly available data sources that identify ecosystem extent, condition and ES flows, we found that it is not possible to develop a physical or monetary natural capital accounts for London for each year between the years 2007 and 2018. However, it was possible to develop a limited urban natural capital account when the year remained unspecified. Although this does not adhere to the strict definition for developing an inclusive natural capital account for London, use of publicly available data on ecosystem extent, ecosystem condition and ES flow with no specified year does enable the development of a limited natural capital account as previous studies have done (EFTEC, 2017; Vivid Economics, 2017a).

\section{DISCUSSION}

Our results were a first attempt to explore whether the development of an urban natural capital account for London was feasible. Our results showed that it was not possible to compile an inclusive natural capital account for London according to the SEEA EEA framework. We did not find publicly available data for key provisioning, regulating and cultural ES, while we found no data for certain years between 2007 and 2018, indicating that currently only a natural capital account with limited scope and time-coverage was possible. Our paper also highlighted 7 mutually exclusive urban land covers that could be used to create an urban natural capital account for London (excluding unspecified green and blue space). Certain urban land covers are heterogeneous and intensively managed, and therefore these natural or semi-natural land covers might not always be easily categorised into a particular land cover. For example, engineered or designed natural assets such as green roofs and walls can be a mosaic of vegetated and impervious land covers, and are better classified as unspecified green or blue 
space as suggested by SEEA experts (Wang et al., 2019). Overall, our results highlighted that a considerable effort is needed to (1) address data gaps on ecosystem extent, condition and ES flows, and (2) improve our understanding of the linkages between ecosystem extent, condition and ES flows as discussed in section 4.1 and 4.2 .

\subsection{DATA GAPS}

Institutions and other organisations need to make a concerted effort to address the data gaps found in this paper. Without addressing these needs, it will remain problematic to develop an urban natural capital account for London according to the SEEA EEA framework. We identified three main reasons for the data gaps related to ecosystem extent and condition, i.e. issues related to (1) temporal inconsistencies, (2) land cover classifications, and (3) lack of public access to certain data sources. Stock take over time, which includes ecosystem extent and condition, is a key component of accounting. Accounts are ideally created based on data sources containing similar sampling approaches at regular time intervals. In our analysis however, 14 out of 29 data sources for ecosystem extent had no identifiable time of sampling, while 2 other data sources from GiGL were sampled before 2007 (i.e. Biodiversity Action Plan habitat data from 1989 and 1995). The remaining data sources for ecosystem extent (i.e. 15 out of 29) were able to cover each land cover annually, but this was dependent on the granular data from the ESA CCI as indicated in Section 3.1 (Figure 2). Some experts argue that ecosystem extent and condition indicators do not change that readily and are burdensome to maintain annually, especially in an urban context. Although this implies a natural capital account would not be fully compliant with the SEEA EEA framework, it does provide a practical solution to a lack of annual data as has been done in previous studies (EFTEC, 2017; Vivid Economics, 2017b).

A number of data sources did not classify urban ecosystems according to a particular land cover, but rather classified spaces based on land uses such as public parks, school grounds or cemeteries. For example, the OS MasterMap Greenspace layer only had one identifiable urban land cover, i.e. agricultural land (incl. allotments), while all other spaces were classified in our analysis as unspecified green space (OS, 2004). Although these data sources were accurate, classification according to land use instead of land cover is not always useful for estimating ecosystem extent. Sometimes land use can infer a particular land cover such as bowling green, which is a close-mown stretch of grassland used for playing particular sports. However, other land uses such as religious grounds or cemetery may have varying land covers such as Abney Park, which is an old forested cemetery, while the old and new Camberwell cemetery consist of well-maintained grasslands. Therefore, land use is not always useful for assessing urban land cover and developing a natural capital account. Certain data sources also require greater detail for use in an urban context. For example, the Land Cover Map from 2007 and 2015 classified pixels according to 21 terrestrial and freshwater habitats outlined by the UK Biodiversity Action Plan (CEH, 2017; Jackson, 2000). However, most of London was classified as a single land cover (i.e. urban land cover), making this data source more useful on a national level but less detailed for identifying smaller areas of natural or semi-natural land cover in London.

Lack of access to certain data sources could address important data gaps for developing a natural capital account for London. For example, the i-Tree Eco London survey was undertaken in 2014 to collect data on single trees and plots of trees in London (Treeconomics London, 2015). The survey 
found that London's urban forest comprised of more than 8 million trees and supports valuation of a variety of ecosystem services such a carbon capture and storage, rainwater interception and removal of air pollution (Treeconomics London, 2015). Similarly, private utility companies such as Thames Water and Affinity Water provide Londoners with water and sewerage services, but data on water assets are scarce and often not publicly available. Lack of access to certain data sources makes it difficult for developing an inclusive London's natural capital account. Resolving data privacy issues and making data sources publicly available are a key component for developing an inclusive natural capital account for London according to the SEEA EEA framework.

\subsection{LINKAGES BETWEEN ECOSYSTEM EXTENT, CONDITION AND ES FLOWS}

Current lack of understanding of the interlinkages between ecosystem extent, condition and ES flows is complicated because these interlinkages are multi-dimensional, multi scale, and non-linear (Mace, 2019). For example, low levels of habitat fragmentation do not necessarily affect pollination services until a tipping-point is reached, after which pollination services reach a alternative stable state (Selkoe et al., 2017). Attempts to connect ecosystem extent and condition to ES flows becomes complicated., suggesting that institutions and other organisations need to cooperate to address these knowledge gaps in the interpretation and use of ecosystem accounts (Maes et al., 2019). This also suggests that communication between institutions and other organisations needs to be facilitated (Maes et al., 2019). For example, both Defra, ONS and GLA are working on the development of urban natural capital accounts. Increased collaboration and sharing practices could enhance overall outcomes for urban natural capital accounting. In 2015, the United Nations Statistical Division (UNSD) in collaboration with the UN Environment Programme, the World Bank and the European Union organised the Forum of Experts in SEEA EEA which was set up to connect stakeholders and share best practices on experimental ecosystem accounting. This Forum seeks to build on existing methods and practices to expand the international framework for environmentaleconomic accounting. Similarly, Defra in collaboration with different UK research councils organised the Valuing Nature Programme with the aim to fund research and support researchers in making links with policymakers, business and practitioners. It is uncertain however whether sharing platforms such as the Forum of Experts in SEEA EEA or the Valuing Nature Network will bring about improvements in cross-disciplinary communication, research on knowledge gaps, and development of publicly available data sources.

\section{CONCLUSIONS}

Our findings showed that building an inclusive natural capital account for London was currently not possible with a simplified urban land cover classification based on the SEEA CF and SEEA EEA. A more simplified urban land cover classification was preferred for classifying urban ecosystems and building an urban natural capital account because the land cover classifications from SEEA CF and SEEA EEA were (1) too detailed for practical use in urban areas or (2) simply not applicable to our study area of Greater London. Furthermore, the lack of temporal availability of data sources for all urban land cover classifications further complicates the development of an urban natural capital account for London consistent with SEEA EEA. However, it is argued by some experts that particular ecosystem extent and condition indicators may not change that readily- especially in urban areas - and could be used for multiple years. Based on our findings, we translate the challenges to develop urban natural capital accounts and advance urban research more broadly in two parts: 
- Renewed efforts are needed to develop better publicly available data sources. By addressing key gaps such as temporal inconsistencies and lack of public access, more data sources could become available that are publicly accessible and updated annually. This would support researchers and decision-makers in their efforts to develop urban natural capital accounts according to the SEEA EEA framework.

- Publicly available data sources need to be underpinned by a cohesive classification framework, which includes realistic land cover classifications for urban ecosystems. By addressing silo-thinking between academic institutions, decision-makers and the private sector, and making interdisciplinary work standard practice, more cohesive data sources may become available for the development of urban natural capital accounts. This could increase support for including new guidelines in the SEEA EEA guidelines particularly for urban ecosystems, and some of this work is already under way (Wang et al., 2019).

Our paper was framed within the broader discussion on the role of natural capital accounting for urban nature conservation by showing that publicly available data sources were not sufficient to develop an inclusive natural capital accounts for London according to the SEEA EEA framework. Future research could include expanding our analysis for publicly available data sources on ES flows that can be inferred from ES modelling and other techniques, amongst others. The abovementioned steps were suggested to address the challenge of dealing with gaps in the data. Through these steps, researchers and decision-makers are encouraged to contribute to the future management of urban ecosystems and the benefits these can deliver to human health and well-being.

\section{ACKNOWLEDGEMENTS}

We thank Defra for their help providing information during this project. This research is supported with funding of the London Natural Environment Research Council Doctoral Training Programme at the Department of Geography, University College London (NERC Ref: NE/ L002485/1).

\section{CONFLICTS OF INTEREST}

The authors declare no conflicts of interest with this work.

\section{REFERENCES}

CBD, 2010. Conference of Parties Decision X/2. Strategic Plan for Biodiversity 2011-20. Nagoya. CEH, 2017. Land Cover Map 2015: Dataset documentation. Crowmarsh Gifford.

Defra, 2018. A Green Future: Our 25 Year Plan to Improve the Environment. London.

EC, 2011. The EU Biodiversity Strategy to 2020. Brussels.

EFTEC, 2017. A study to scope and develop urban natural capital accounts for the UK. London.

ESA, 2017. Land Cover CCI: Product User Guide Version 2.0.

GIGL, 2017. H003GiGL Data Guide. London.

GLA, 2018. London Environment Strategy. London.

Haines-Young, R., Potschin, M., 2018. Common International Classification of Ecosystem Services (CICES) V5.1. Nottingham.

Han, Y., Wang, Y., Zhao, Y., 2010. Estimating Soil Moisture Conditions of the Greater Changbai Mountains by Land Surface Temperature and NDVI. IEEE Trans. Geosci. Remote Sens. 48, 25092515.

Hein, L., Bagstad, K.J., Obst, C., Edens, B., Schenau, S., Castillo, G., Soulard, F., Brown, C., Driver, A., Bordt, M., Steurer, A., Harris, R., Caparrós, A., 2020. Progress in natural capital accounting for 
ecosystems. Science (80-. ). 367, 514-515.

Jackson, D.L., 2000. Guidance on the interpretation of the Biodiversity Broad Habitat Classification (terrestrial and freshwater types): Definitions and the relationship with other classifications. Peterborough.

Kriegler, F.J., Malila, W.A., Nalepka, R.F., Richardson, W., 1969. Preprocessing Transformations and Their Effects on Multispectral Recognition. Proc. Sixth Int. Symp. Remote Sens. Environ. 97131.

Mace, G.M., 2019. The ecology of natural capital accounting. Oxford Rev. Econ. Policy 35, 54-67.

Maes, M.J.A., Jones, K.E., Toledano, M.B., Milligan, B., 2019. Mapping synergies and trade-offs between urban ecosystems and the sustainable development goals. Environ. Sci. Policy 93, 181-188.

MEA, 2005. Ecosystems and Human well-being: Synthesis. Washington D.C.

NCC, 2013. The State of Natural Capital: Towards a framework for measurement and valuation. London.

ONS, 2019. UK natural capital: urban accounts [WWW Document]. URL https://www.ons.gov.uk/economy/environmentalaccounts/bulletins/uknaturalcapital/urbanac counts (accessed 12.3.19).

OS, 2004. OS MasterMap user guide: product specification preface. Southampton.

Pettorelli, N., Vik, J.O., Mysterud, A., Gaillard, J.M., Tucker, C.J., Stenseth, N.C., 2005. Using the satellite-derived NDVI to assess ecological responses to environmental change. Trends Ecol. Evol. 20, 503-510.

Selkoe, K.A., Blenckner, T., Caldwell, M.R., Crowder, L.B., Erickson, A.L., Essington, T.E., Estes, J.A., Fujita, R.M., Halpern, B.S., Hunsicker, M.E., Kappel, C. V, Kelly, R.P., Kittinger, J.N., Levin, P.S., Lynham, J.M., Mach, M.E., Martone, R.G., Mease, L.A., Salomon, A.K., Samhouri, J.F., Scarborough, C., Stier, A.C., White, C., Zedler, J., 2017. Principles for managing marine ecosystems prone to tipping points. Ecosyst. Heal. Sustain. 1, 1-18.

Stiglitz, J.E., Sen, A., Fitoussi, J.-P., 2010. Mismeasuring Our Lives: Why GDP Doesn't Add Up. The New Press.

Treeconomics London, 2015. Valuing London's urban forest: Results of the London i-Tree Eco Project. London.

UN, 2014a. System of Environmental-Economic Accounting 2012 - Central Framework. New York.

UN, 2014b. System of Environmental-Economic Accounting 2012: Experimental Ecosystem Accounting. New York.

UN, 2015. Resolution adopted by the General Assembly on 25 September 2015 A/RES/70/1 on transforming our world: the 2030 Agenda for Sustainable Development. New York.

UN, 2019. Technical Recommendations in support of the System of Environmental-Economic Accounting 2012: Experimental Ecosystem Accounting. New York.

UN, 2020. SEEA Experimental Ecosystem Accounting Revision [WWW Document]. URL https://seea.un.org/content/seea-experimental-ecosystem-accounting-revision (accessed 7.1.20).

Vardon, M., Bass, S., Sofia Ahlroth, S., Ruijs, A., 2017. Forum on Natural Capital Accounting for Better Policy Decisions: Taking Stock and Moving Forward. Washington D.C.

Vivid Economics, 2017a. Natural capital accounts for public green space in London: Methodology document. London.

Vivid Economics, 2017b. Natural capital accounts for public green space in London. London.

Wang, J., Soulard, F., Henry, M., Grenier, M., Schenau, S., Barton, D., Harris, R., Chan, J.Y., Keith, D., Obst, C., 2019. Discussion paper 1.2: Treatment of ecosystems assets in urban areas. . 


\section{ELECTRONIC SUPPLEMENTARY MATERIAL}

Raw data for answering the methods are available in full in the attached pdf document and can be found in the online version of this article. 


\section{Electronic Supplementary Material}

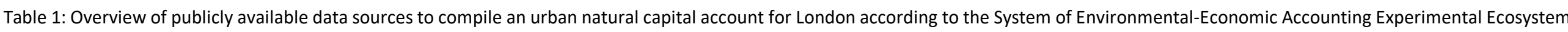
Accounting (SEEA EEA).

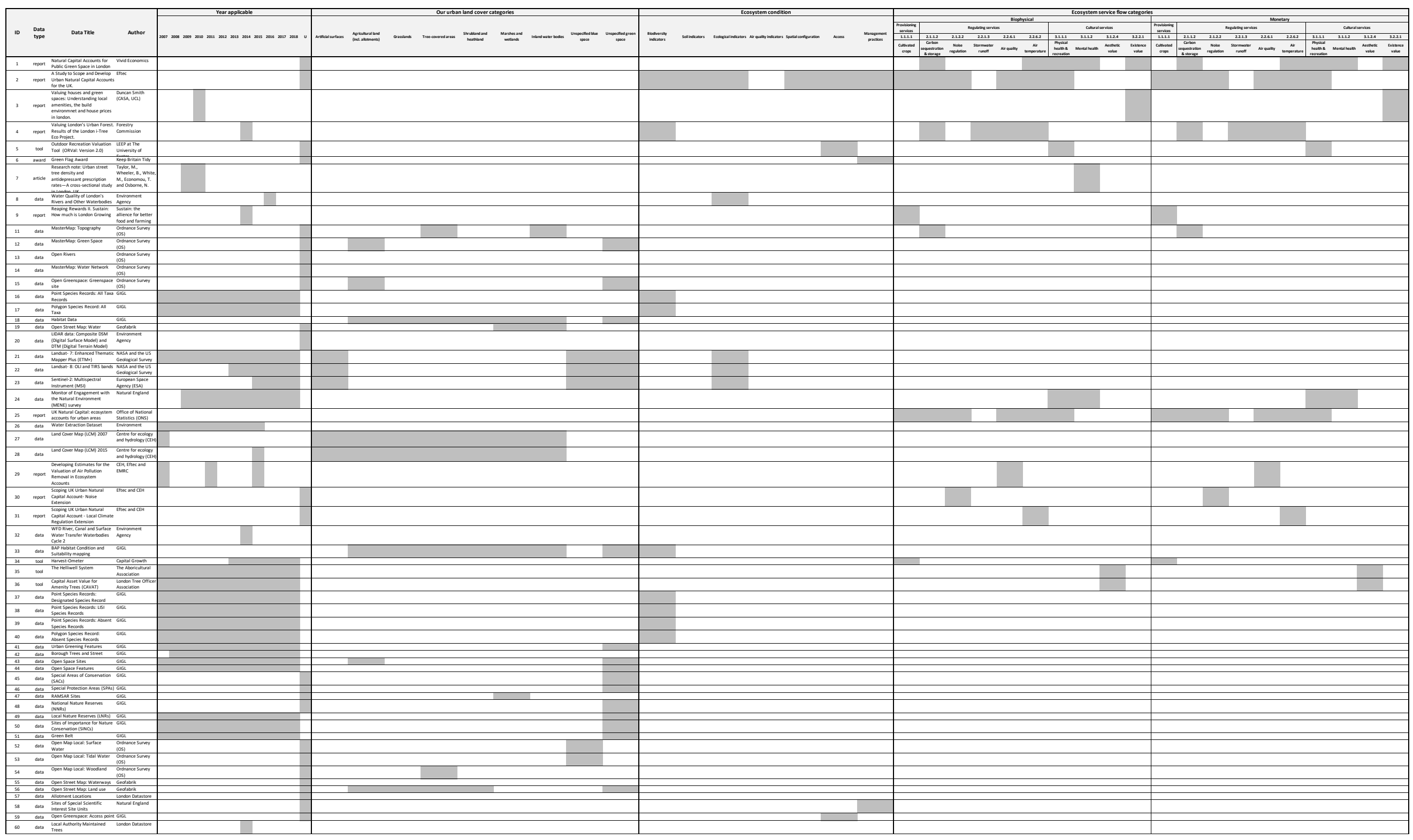




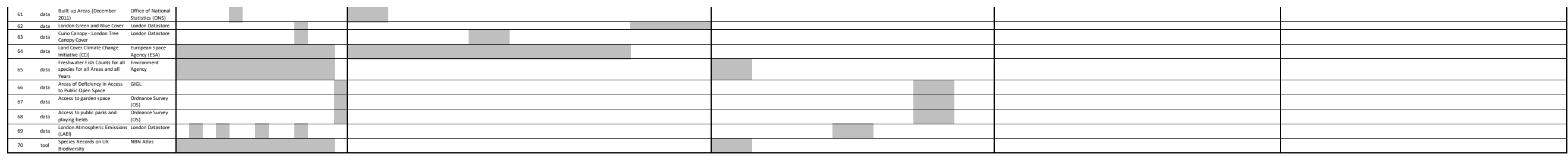


Table 2: Description on identified publicly available data sources to compile an urban natural capital account for London according to the System of Environmental-Economic Accounting Experimental Ecosystem Accounting (SEEA EEA).

We included publicly available data sources with partial spatial or temporal cover for Greater London and gathered information for each mapped data source, if applicable, on authorship, update frequency, spatial extent, unit or resolution, data format (e.g. raster, vector format), licensing or usage restrictions and historic data availability.

\begin{tabular}{|c|c|c|c|c|c|c|c|c|c|c|c|c|c|c|}
\hline 10 Data trpe & oe Data tule & 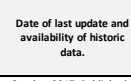 & Seneral Descripition Spantal Scope & Spatata Units & $\begin{array}{c}\text { Land cover/ Ecossstem } \\
\text { Types nncluded }\end{array}$ & 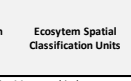 & $\begin{array}{l}\text { Ecossstem Condtion } \\
\text { variables }\end{array}$ & 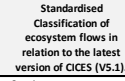 & $\begin{array}{l}\text { Ecosysten Semices } \\
\text { neculued }\end{array}$ & 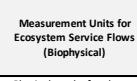 & 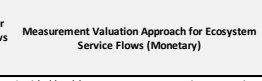 & 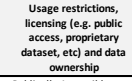 & 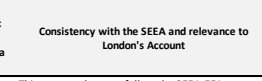 & uRL \\
\hline 1 report & 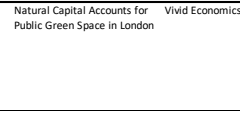 & 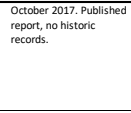 & 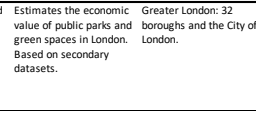 & 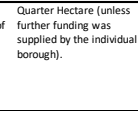 & 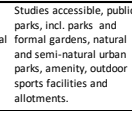 & 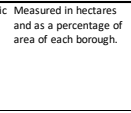 & & & 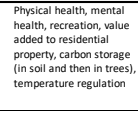 & 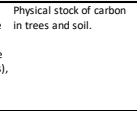 & 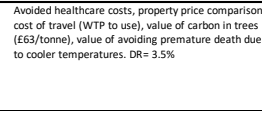 & 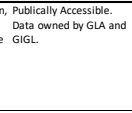 & 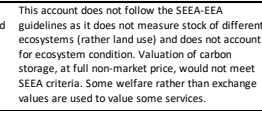 & 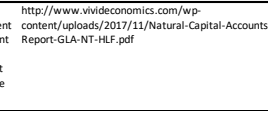 \\
\hline 2 report & 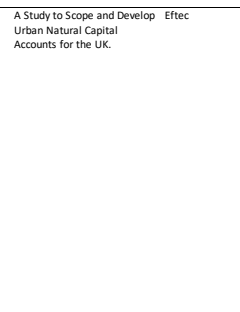 & 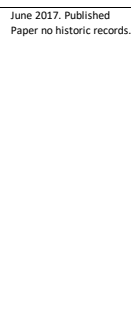 & 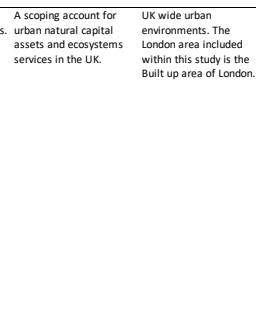 & 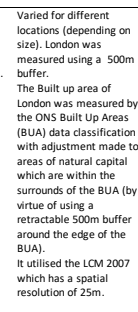 & 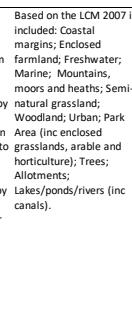 & 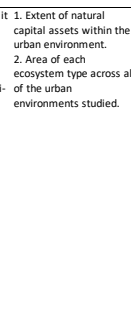 & 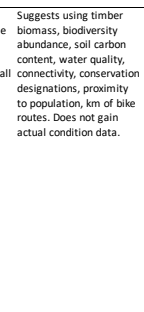 & 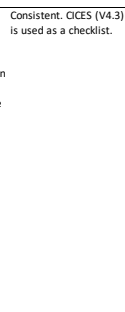 & 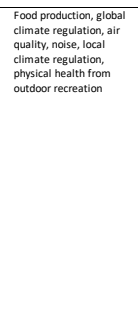 & 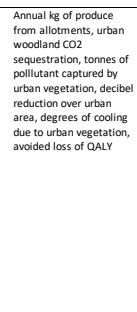 & 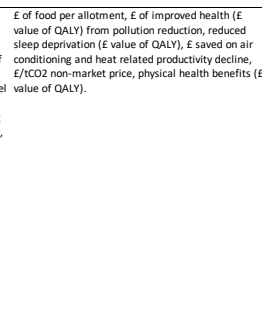 & 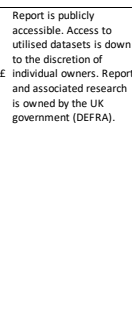 & 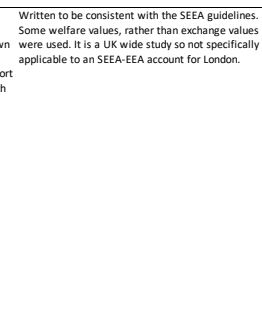 & 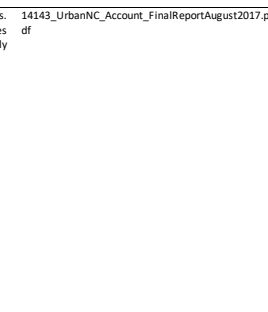 \\
\hline 3 report & 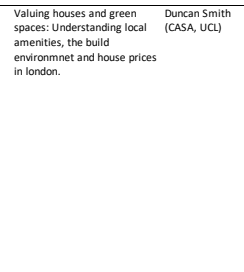 & 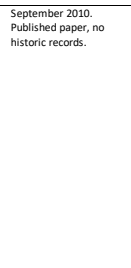 & 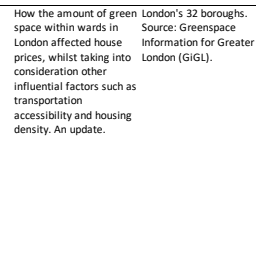 & 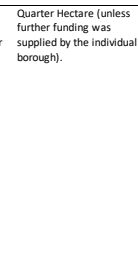 & 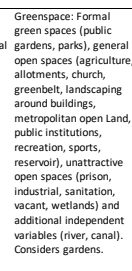 & & Na. & 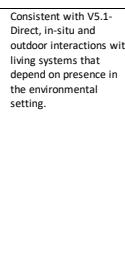 & 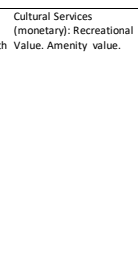 & & 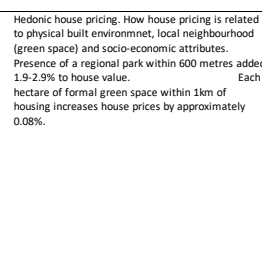 & 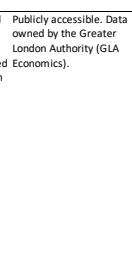 & 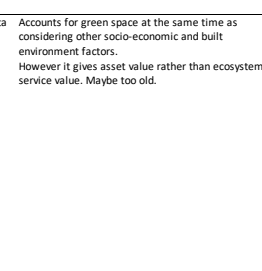 & 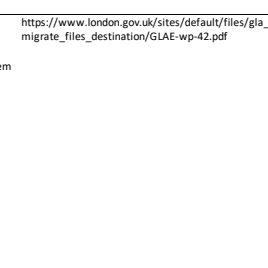 \\
\hline $4 \quad$ report & 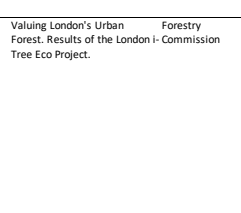 & 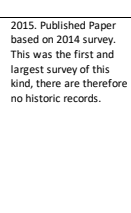 & 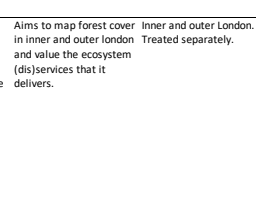 & 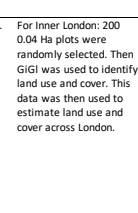 & 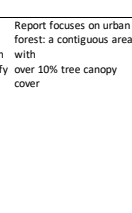 & 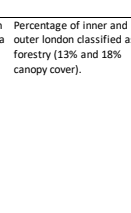 & 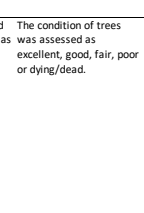 & 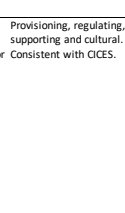 & 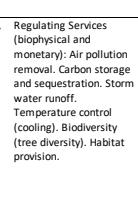 & 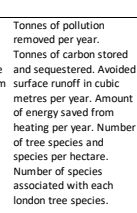 & 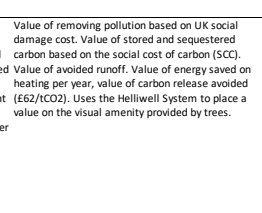 & 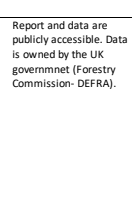 & 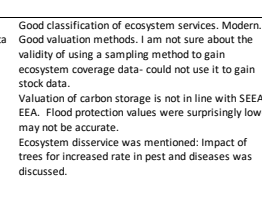 & 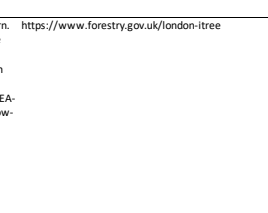 \\
\hline $5 \quad$ tool & 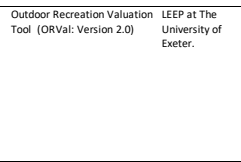 & 2018 & 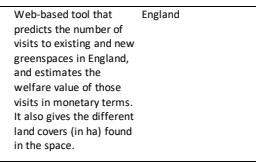 & 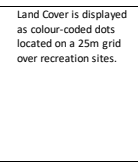 & $\begin{array}{l}\text { Land cover is based on } \\
\text { LCM } 2007 \text { from CEH. }\end{array}$ & & 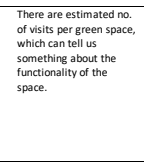 & 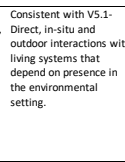 & 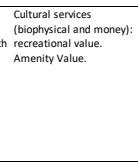 & 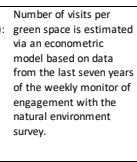 & 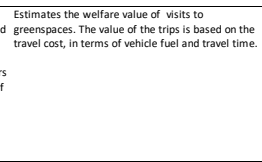 & 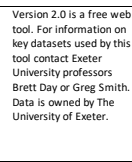 & 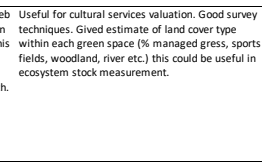 & \\
\hline $6 \quad$ award & $G$ Gren flag Award & & 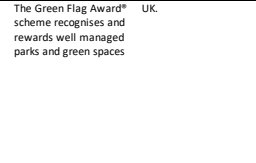 & 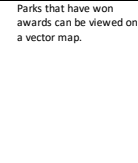 & 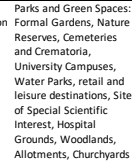 & & 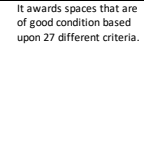 & & & $\mathrm{NA}$. & & 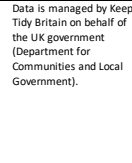 & 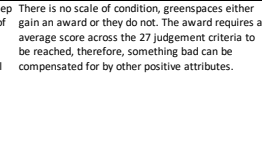 & \\
\hline
\end{tabular}




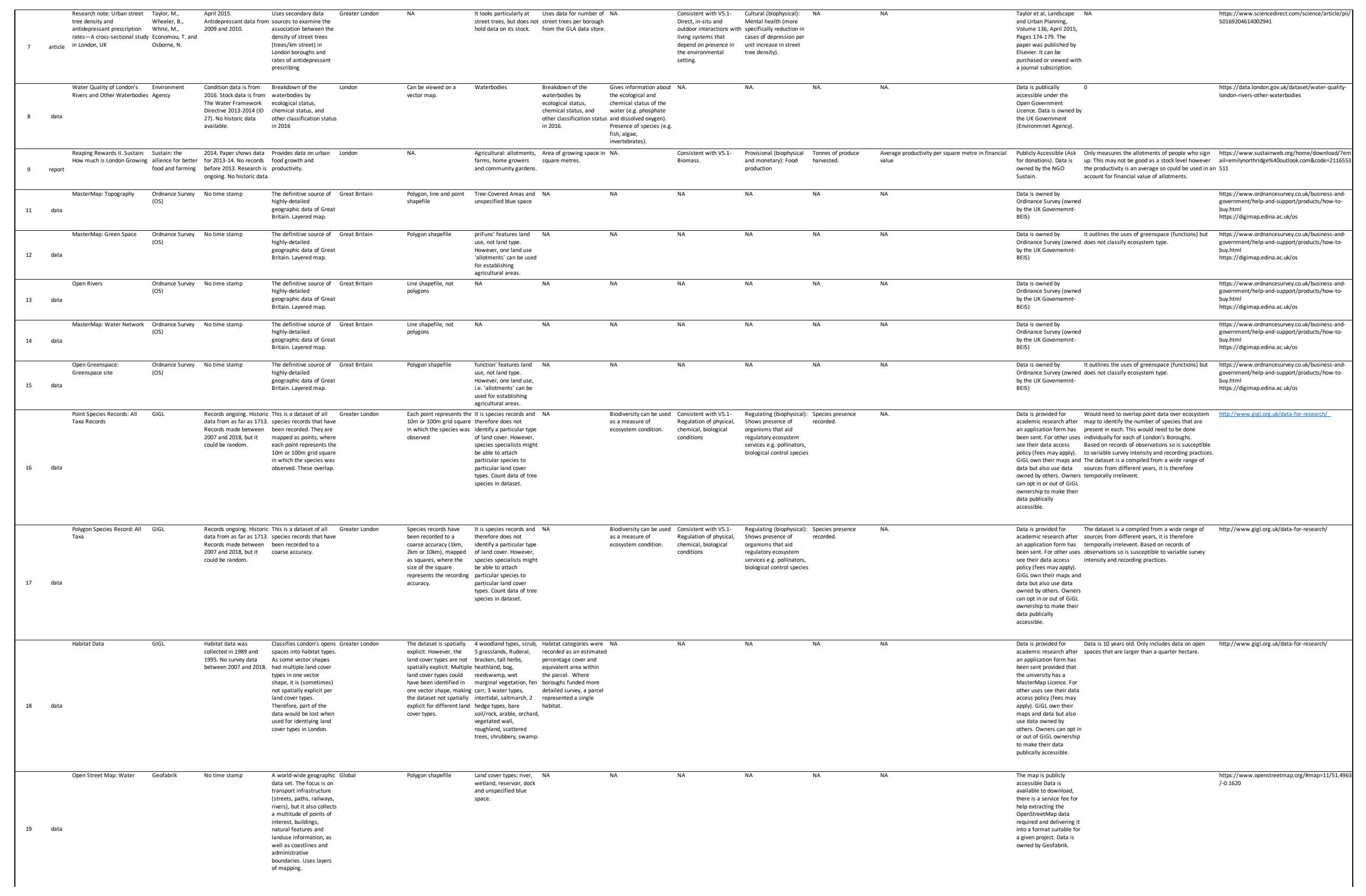




\begin{tabular}{|c|c|c|c|c|c|c|c|c|c|c|c|c|c|}
\hline 20 & data & 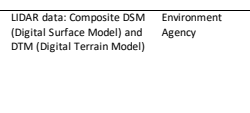 & 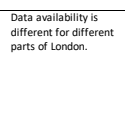 & 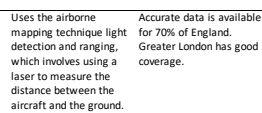 & 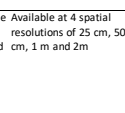 & 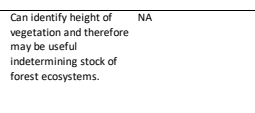 & & & NA & $\mathrm{NA}$ & 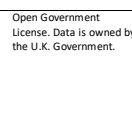 & 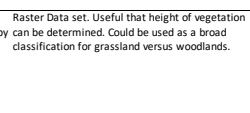 & 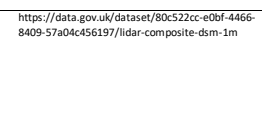 \\
\hline 21 & data & 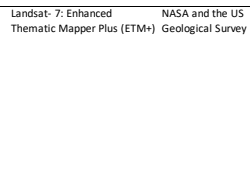 & 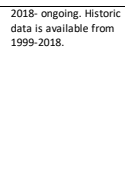 & 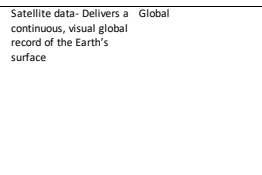 & 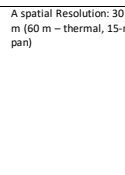 & 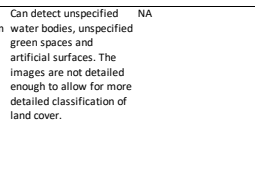 & 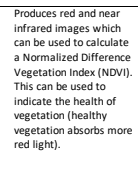 & & NA & $\mathrm{NA}$ & 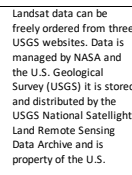 & 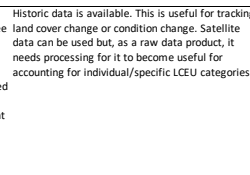 & \\
\hline 22 & data & 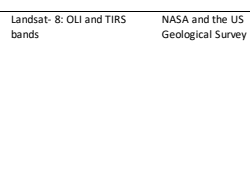 & 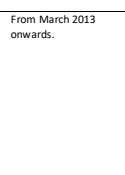 & 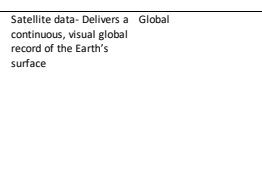 & 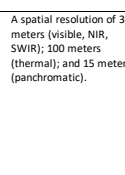 & 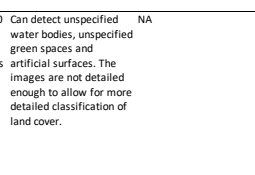 & 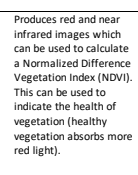 & & NA & ${ }^{N A}$ & 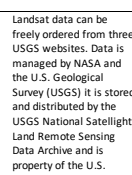 & 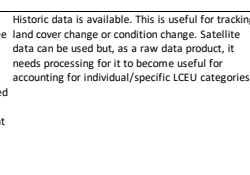 & 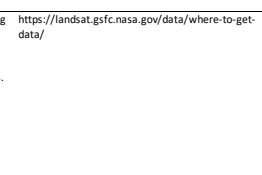 \\
\hline${ }^{23}$ & data & 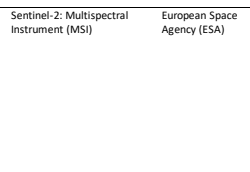 & 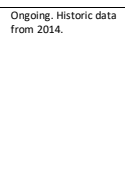 & 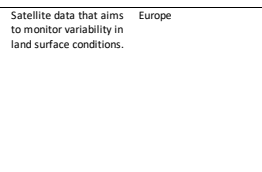 & 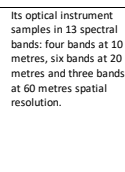 & 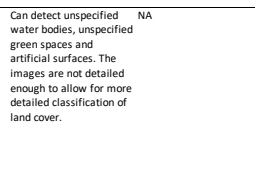 & 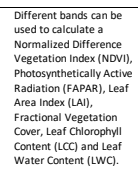 & & NA & $\mathrm{NA}$ & 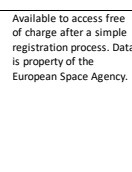 & 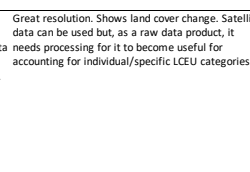 & $\begin{array}{l}\text { tie hitps//sent } \\
\text { access }\end{array}$ \\
\hline 24 & data & 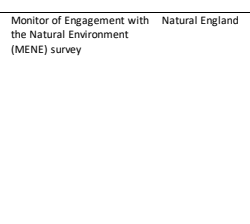 & 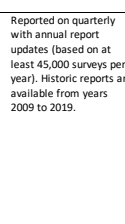 & 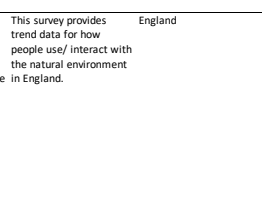 & NA & ${ }^{N A}$ & NA & 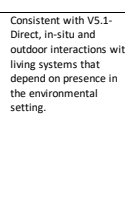 & 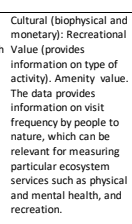 & & 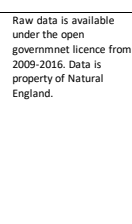 & 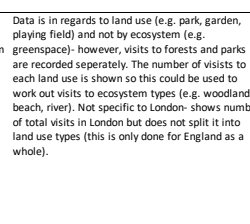 & 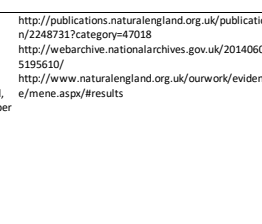 \\
\hline 25 & repore & 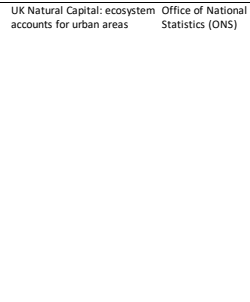 & 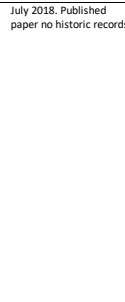 & 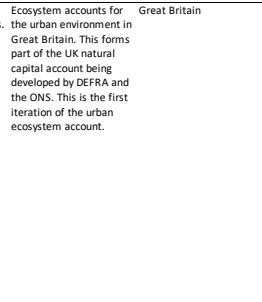 & 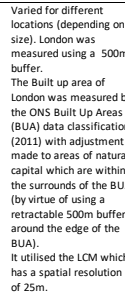 & 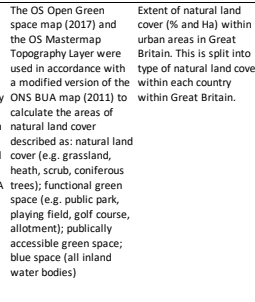 & 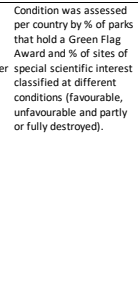 & 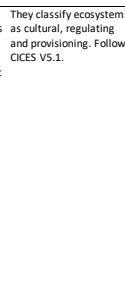 & 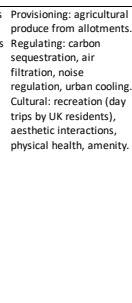 & 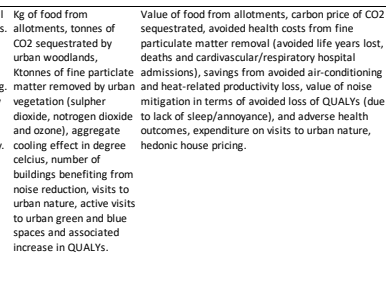 & 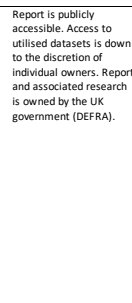 & 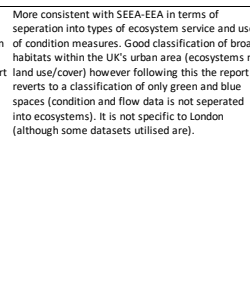 & 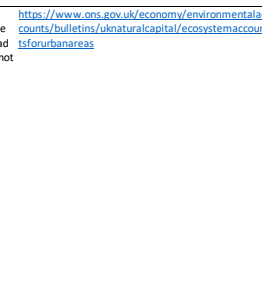 \\
\hline${ }^{26}$ & data & 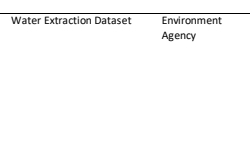 & 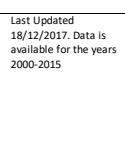 & 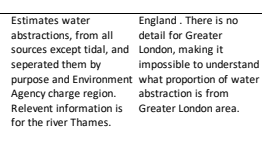 & & 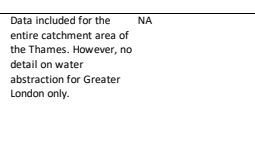 & $\mathrm{NA}$ & 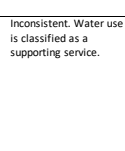 & 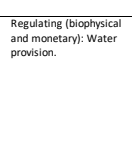 & 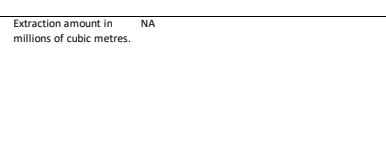 & 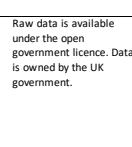 & 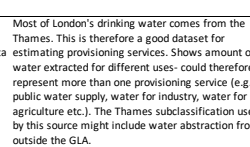 & 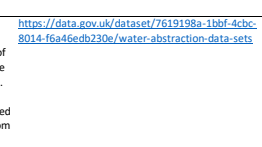 \\
\hline 27 & data & 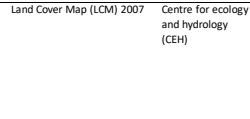 & 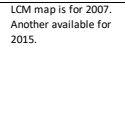 & 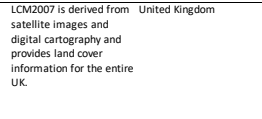 & Polven shaperfile & 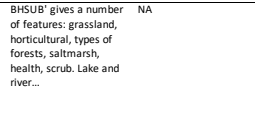 & $\mathrm{NA}^{\mathrm{NA}} \mathrm{C}-\mathrm{l}$ & NA & $N A$ & $\mathrm{NA}^{\mathrm{NA}} \mathrm{C}-\mathrm{Cl}$ & 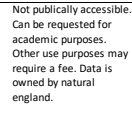 & 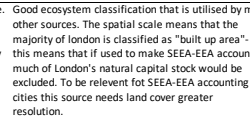 & \\
\hline 28 & data & 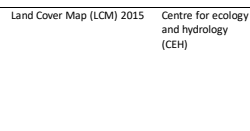 & & 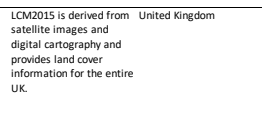 & & 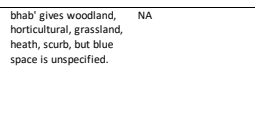 & $\mathrm{NA}$ & NA & $\mathrm{NA}$ & & 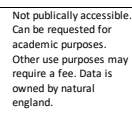 & 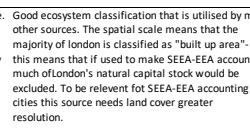 & \\
\hline
\end{tabular}




\begin{tabular}{|c|c|c|c|c|c|c|c|c|c|c|c|c|c|c|}
\hline 29 & report & 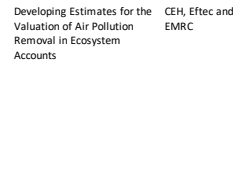 & 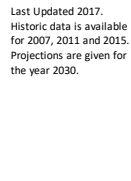 & 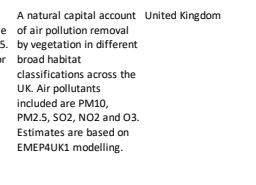 & 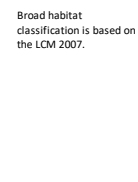 & 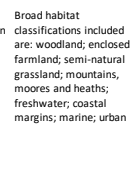 & 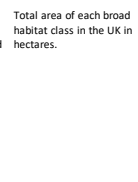 & & 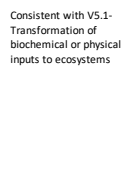 & 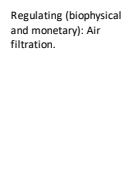 & 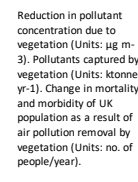 & 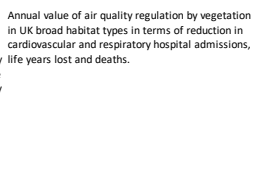 & 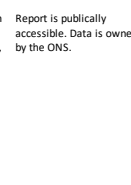 & 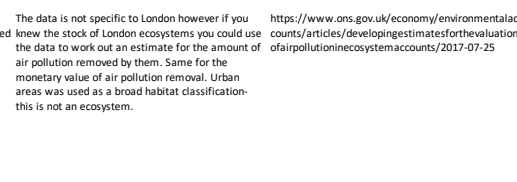 \\
\hline${ }_{30}$ & report & 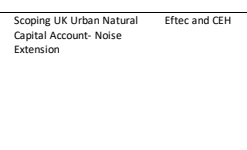 & 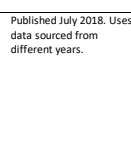 & 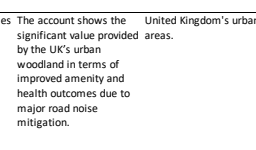 & 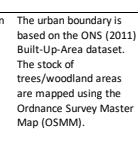 & "1) woodande & 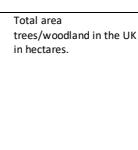 & 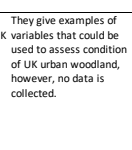 & 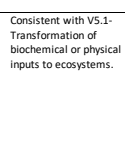 & 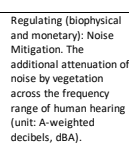 & 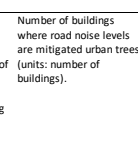 & 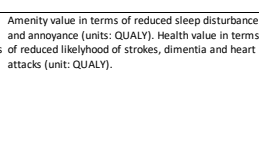 & 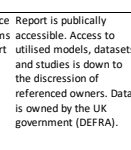 & 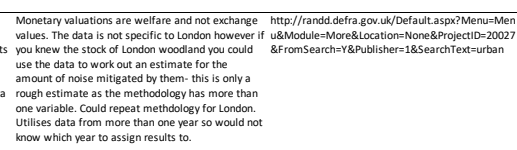 \\
\hline${ }^{31}$ & report & 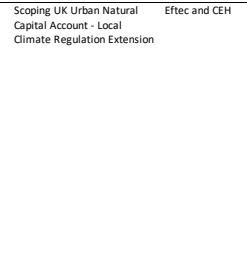 & 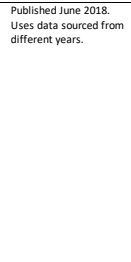 & 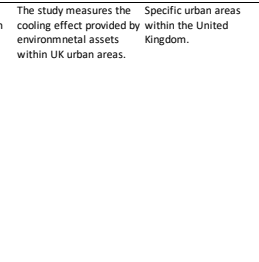 & 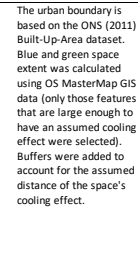 & 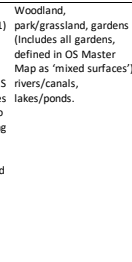 & 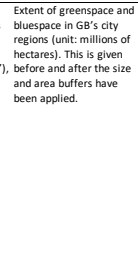 & 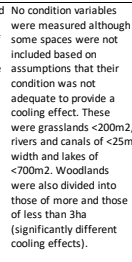 & 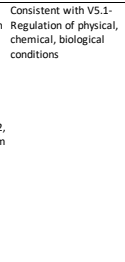 & 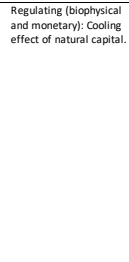 & 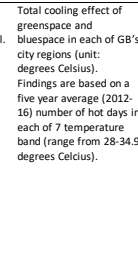 & 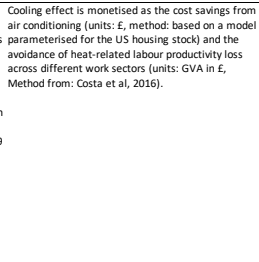 & 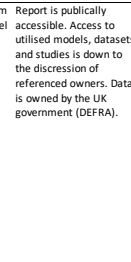 & 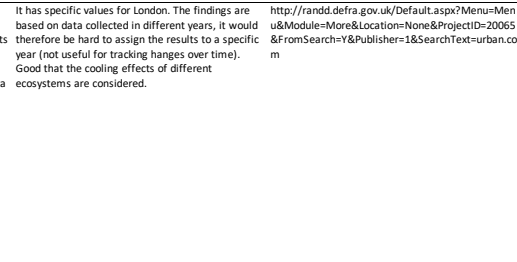 \\
\hline 32 & data & 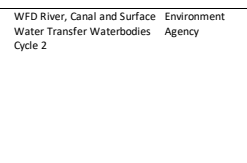 & 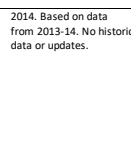 & 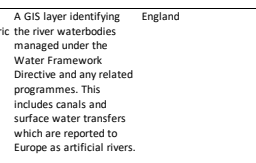 & 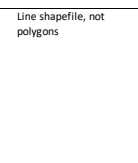 & 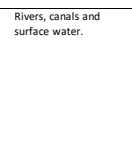 & 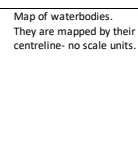 & & NA & $\mathrm{NA}$ & $\mathrm{NA}^{\mathrm{Na}}$ & Na & 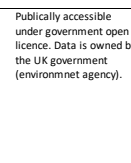 & 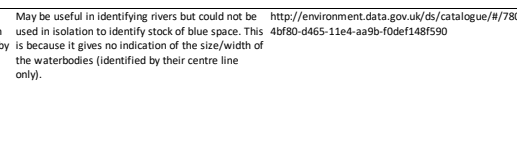 \\
\hline 33 & data & 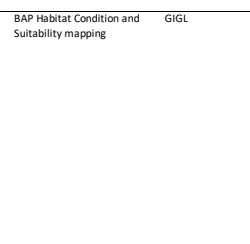 & 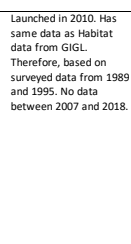 & 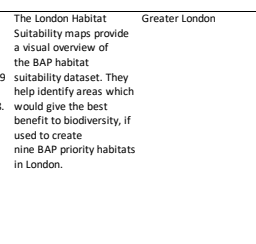 & 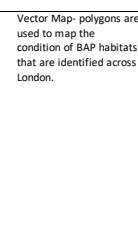 & 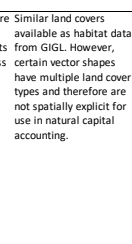 & & 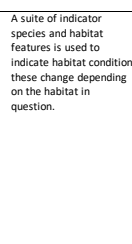 & & NA & Na & NA & 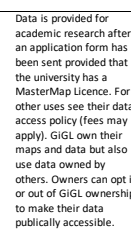 & 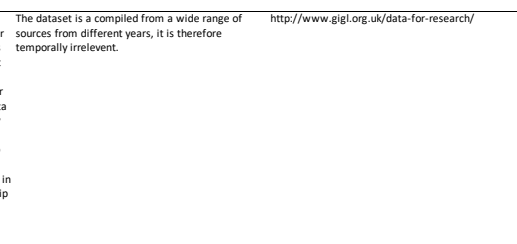 \\
\hline${ }^{34}$ & tool & Havest:-Ometer & 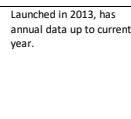 & 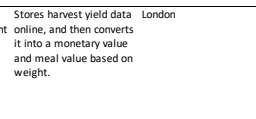 & ${ }^{\mathrm{NA}}$ & NA & NA & NA & 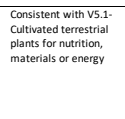 & 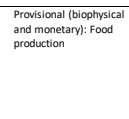 & $\begin{array}{l}\text { Weigh of food prodiced } \\
\text { (tonnes) }\end{array}$ & 1 valle of fod od gown. & 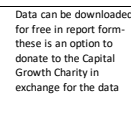 & 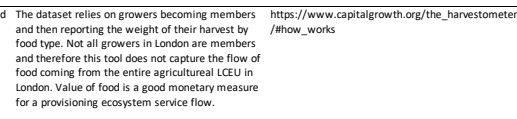 \\
\hline 35 & tool & The Hellivel IS Ssitem & 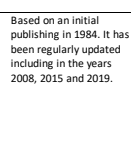 & 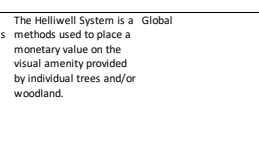 & NA & Tree-Covered Afeas & Na. & NA. & 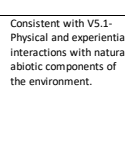 & 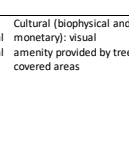 & 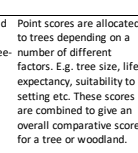 & 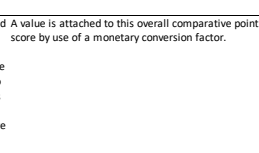 & & 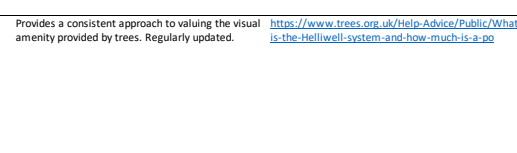 \\
\hline 36 & tool & 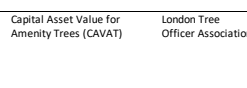 & 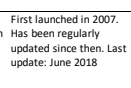 & 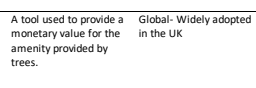 & Na & Treec-Covered Areas & NA. & Na & 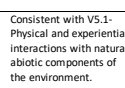 & 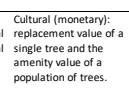 & & 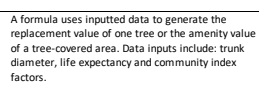 & 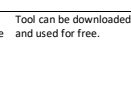 & 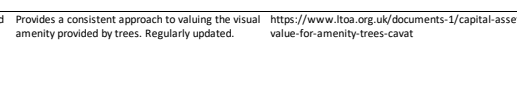 \\
\hline${ }^{37}$ & data & 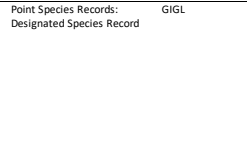 & 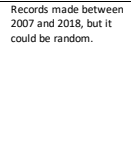 & 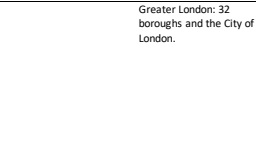 & 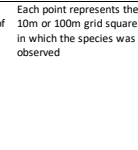 & 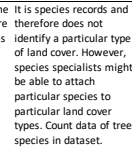 & & $\overline{N A N}$ & & & & & & \\
\hline
\end{tabular}




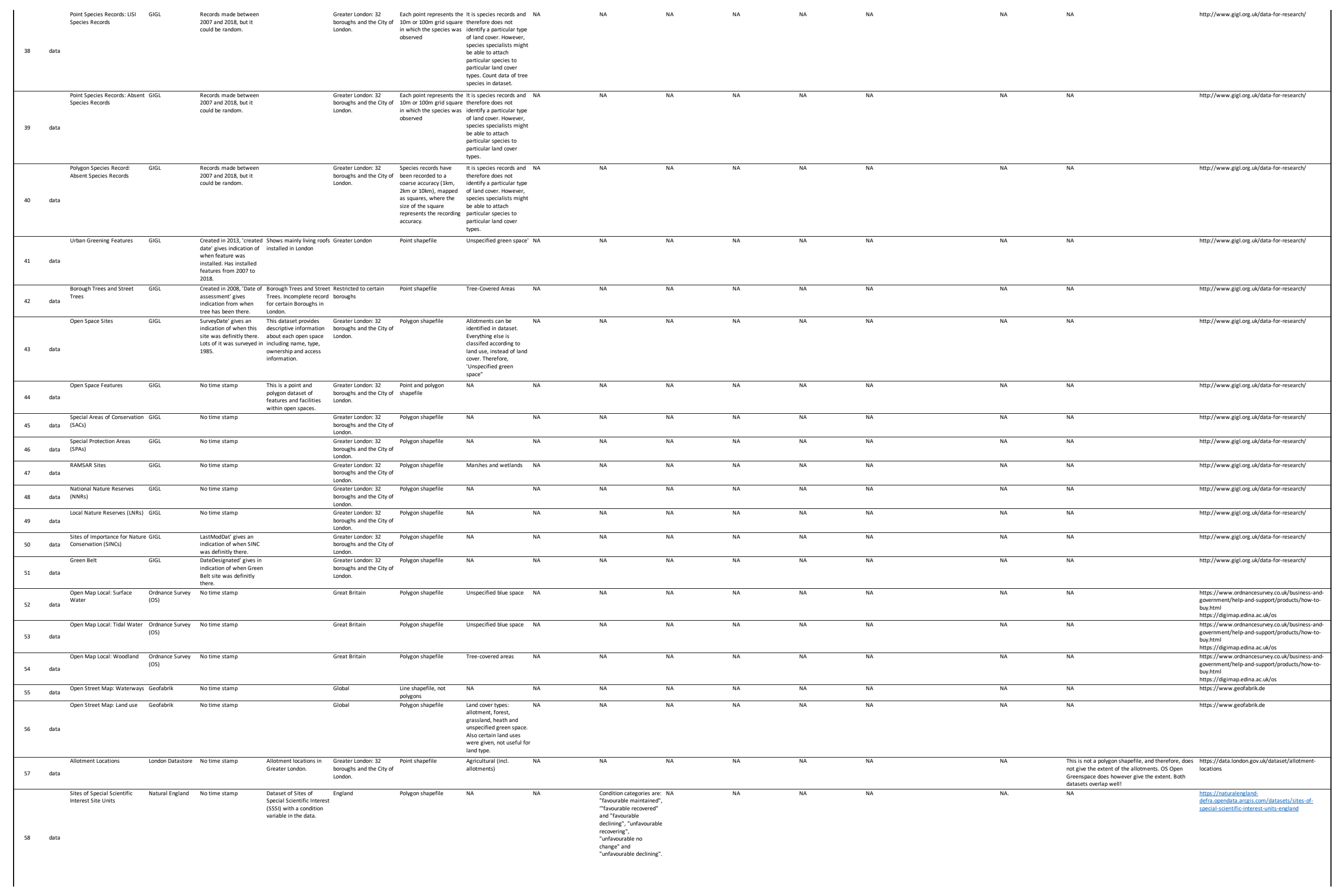




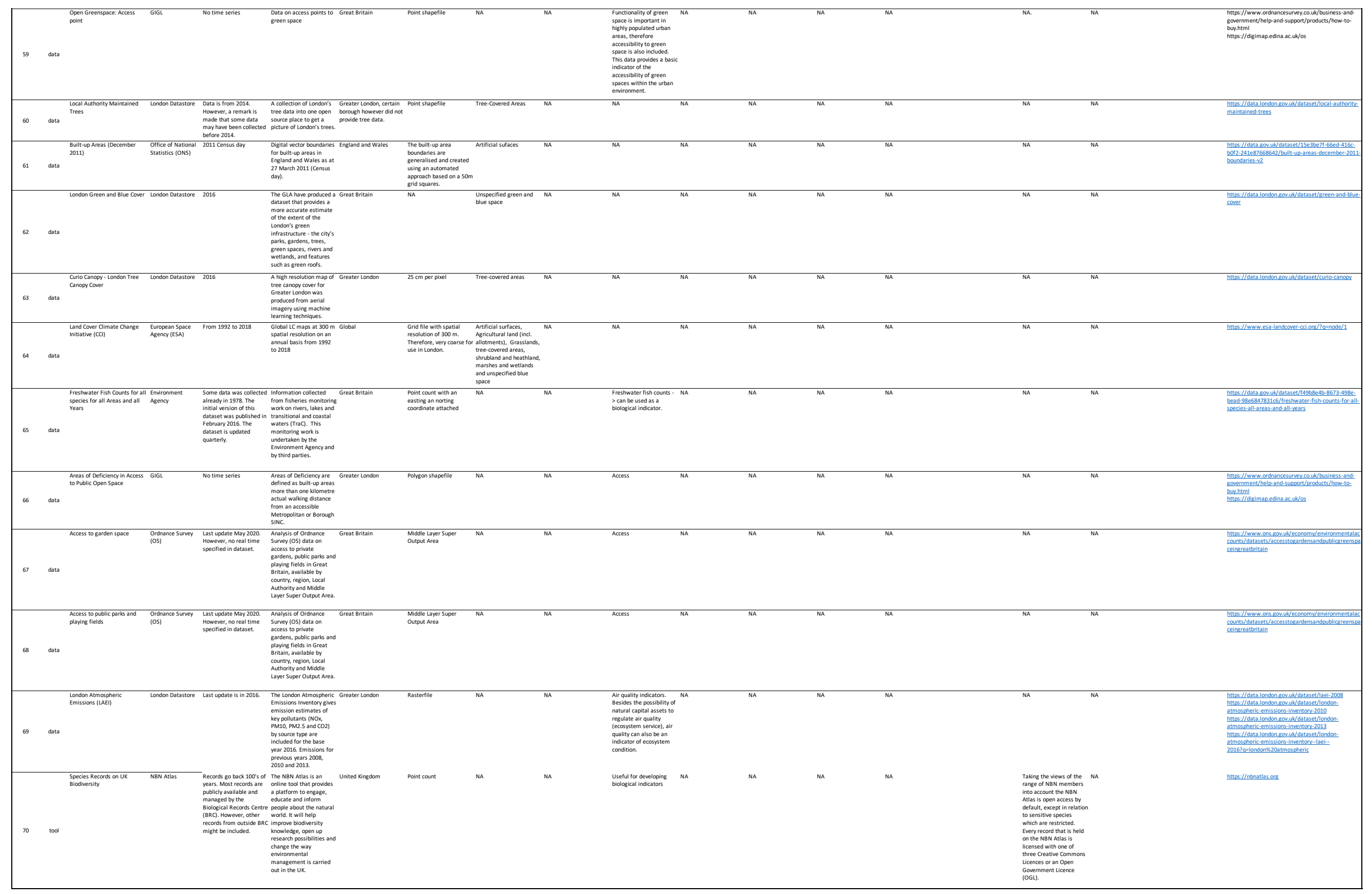


Table 3: Matrix linking ecosystem extent and condition to ecosystem service flows

\begin{tabular}{|c|c|c|c|c|c|c|c|c|c|c|}
\hline & \multicolumn{10}{|c|}{ Ecosystem service flow } \\
\hline & $\begin{array}{l}\text { Cultivated } \\
\text { crops }\end{array}$ & $\begin{array}{c}\text { Carbon } \\
\text { sequestration } \\
\& \text { storage }\end{array}$ & $\begin{array}{l}\text { Noise } \\
\text { regulation }\end{array}$ & $\begin{array}{l}\text { Stormwater } \\
\text { runoff }\end{array}$ & Air quality & $\begin{array}{l}\text { Air } \\
\text { temperature }\end{array}$ & $\begin{array}{l}\text { Physical health } \\
\text { \& recreation }\end{array}$ & Mental health & $\begin{array}{l}\text { Aesthetic } \\
\text { value }\end{array}$ & $\begin{array}{l}\text { Existence } \\
\text { value }\end{array}$ \\
\hline \multicolumn{11}{|l|}{ Ecosystem extent } \\
\hline \multirow{2}{*}{\multicolumn{11}{|c|}{$\begin{array}{l}\text { Agricultural land (incl. allotments) } \\
\text { Grasslands }\end{array}$}} \\
\hline & & & & & & & & & & \\
\hline \multicolumn{11}{|l|}{ Tree-covered areas } \\
\hline \multicolumn{11}{|l|}{ Shrubland and heathland } \\
\hline \multicolumn{11}{|l|}{ Marshes and wetlands } \\
\hline \multicolumn{11}{|l|}{ Inland water bodies } \\
\hline \multicolumn{11}{|l|}{ Ecosystem condition } \\
\hline \multirow{2}{*}{\multicolumn{11}{|c|}{$\begin{array}{l}\text { Biodiversity indicators } \\
\text { Soil indicators }\end{array}$}} \\
\hline \multirow{2}{*}{\multicolumn{11}{|c|}{ Soil indicators }} \\
\hline & & & & & & & & & & \\
\hline \multicolumn{11}{|l|}{ Air quality indicators } \\
\hline \multicolumn{11}{|l|}{ Spatial configuration } \\
\hline Access & & & & & & & & & & \\
\hline Management practices & & & & & & & & & & \\
\hline
\end{tabular}

